\title{
¿SEXUALIDAD NORMAL/SEXUALIDAD PATOLÓGICA? ANÁLISIS DE LA CONCEPCIÓN DE SEXUALIDAD DICOTÓMICA DEL PSICOANALISTA OTTO KERNBERG
}

\section{NORMAL SEXUALITY OR PATHOLOGICAL SEXUALITY? ANALYSIS OF THE DICHOTOMOUS SEXUALITY CONCEPTION OF THE PSYCHOANALYST OTTO KERNBERG}

\section{Daniela Szuster*}

\begin{abstract}
RESUMEN
Este artículo propone analizar la concepción dicotómica entre sexualidad normal/ sexualidad patológica presentada en el libro Relaciones amorosas: normalidad y patología del psicoanalista Otto Kernberg con el fin de interrogar la manera tradicional en que se concibe la sexualidad humana.
\end{abstract}

PALABRAS CLAVES: SEXUALIDAD * DIVERSIDAD * PSICOANÁLISIS * TEORÍA * ANÁLISIS

SUMMARY

This article proposes the analysis of the dichotomous conception of normal/ pathological sexuality presented in the book "Love Relations: Normality and Pathology", by psychoanalyst Otto Kernberg, so as to question the traditional way in which human sexuality is conceived.

KEY WORDS: SEXUALITY $*$ DIVERSITY $*$ PSYCHOANALYSIS $*$ THEORY $*$ ANALYSIS

Congregación B'nei Israel

danielaszuster@yahoo.com.ar 


\section{INTRODUCCIÓN}

La psiquiatría y el psicoanálisis son disciplinas que han servido, y sirven, como elementos esenciales para la construcción de las mentes, cuerpos, deseos y fantasías. Sus invenciones $y$ discursos han calado hondo en las subjetividades modernas, hasta el punto de haber naturalizado sus estigmas y clasificado categóricamente a los seres humanos en torno al desarrollo de sus sexualidades por sus conductas, deseos y prácticas.

El objetivo de este artículo es analizar la manera en que el libro Relaciones amorosas: normalidad y patología del psicoanalista Otto Kernberg concibe la sexualidad humana, con el fin de visibilizar la limitación que tienen teorías de ese estilo, en el modo de pensar la sexualidad humana y las consecuencias de esas ideas. Este ensayo rastrea las bases del pensamiento freudiano en la teoría del psiquiatra Krafft-Ebing -el primero en introducir el término perversión en una obra científica, y en hacer una clara división entre sexualidad normal y sexualidad patológica-. A continuación, el texto examina dicho concepto en dos artículos de la obra de Sigmund Freud. Por último, analiza específicamente la perspectiva dicotómica de la sexualidad, expuesta en el libro Relaciones amorosas: normalidad y patología del psicoanalista Otto Kernberg ${ }^{1}$. La elección de este título se debe,

Otto Kernberg nació en Viena en 1928. Es psicoanalista y Profesor de Psiquiatría del Centro de Entrenamiento e Investigación Psicoanalíticos de la Universidad de Columbia. También es Profesor de Psiquiatría en el Medical College de la Universidad de Cornell y Presidente Asociado y Director Médico del New York Hospital, Cornell Medical Center, Westchester Division.

Kernberg es conocido por sus teorías psicoanalíticas sobre personalidades límites y patologías narcisistas. Se ha destacado por integrar la Psicología del Yo, de la posguerra (desarrollado en sus comienzos en EEUU e Inglaterra), con la Teoría de las Relaciones Objetales, de Melanie Klein.

Los textos de Kernberg son centrales en el desarrollo de una Moderna Teoría de Relaciones Objetales, una de las más aceptadas dentro del psicoanálisis.

En 1972 Otto Kernberg ganó el premio Heinz Hartmann, del Instituto y Sociedad Psicoanalítica de Nueva York. Es autor de varios libros. entre otras cosas, a que fue escrito en 1995, se publicaron varias ediciones, y sigue vendiéndose en librerías costarricenses; lo que indica que es una obra vigente, aplicada por psicoanalistas en sus trabajos terapéuticos.

El psicoanálisis es un campo inmenso. Este artículo analiza la teorización del psicoanalista Otto Kernberg, teniendo en cuenta que existen diferencias con otros profesionales, con diferentes enfoques.

El desarrollo teórico elaborado por Otto Kernberg presenta una manera dicotómica de entender, catalogar, diagnosticar y tratar la sexualidad humana: sexualidad normal/sexualidad patológica, pierde de vista las múltiples y complejas maneras humanas de entenderla.

\section{SEXUALIDAD DICOTÓMICA EN FREUD}

Como es sabido, Freud hizo un giro copernicano dentro del conocimiento de la sociedad occidental en torno a la sexualidad, en particular, $y$ en la manera de comprender y analizar la psique humana, en general. Sus ideas y pensamientos, sin duda, tienen validez hasta hoy. Aun así, sus concepciones limitan notablemente la manera que tenemos de entender y concebir la sexualidad, en especial en relación con el concepto de perversión.

Al hablar de perversión en materia de sexualidad, es imprescindible nombrar al primer psiquiatra que usó este término de manera científica en el siglo XIX: Krafft-Ebing. Su obra Psichopathia Sexualis, publicada en 1886, intentó hacer un estudio sistemático de la sexualidad y sus perturbaciones por medio del método descriptivo empirista de la Psiquiatría Clásica, de forma neutra y sin juicio de valor. Ese fue el objetivo, sin embargo, Krafft-Ebing no lo logró. Es claro que la obra está constituida sobre una determinada ideología y ciertos principios morales. Roberto Mazzuca postula:

Debemos también hacer notar que, a pesar de la enorme empresa realizada para despojar a esas formas de consideraciones de valor $y$ darle un tratamiento científico, el concepto de perversión, tal cual lo forjó Krafft-Ebing, conserva un 
núcleo irreductible de juicio moral. Para que una conducta pueda definirse como desviada es necesaria su comparación con un modelo ideal considerado normal. Y este modelo no es nunca ajeno a los valores morales y culturales de la época (2001:3).

Krafft-Ebing define como perversa, toda manifestación del instinto sexual que no esté de acuerdo con los objetivos de la naturaleza, es decir, que no tengan por finalidad, la procreación (1886:52-53). Esta es la línea divisoria entre normalidad y patología. En su obra Psichopathia Sexualis, siguiendo la definición de perversión citada, Kraft-Ebbing desarrolló de manera descriptiva las distintas formas de desviaciones sexuales. Confecciona una especie de catálogo de perversiones, aparecen: sadismo, fetichismo, masoquismo, exhibicionismo, voyerismo, zoofilia y homosexualidad. siones:

Krafft-Ebing divide dos grupos de perver-

1) Aquellas en las que lo perverso es la finalidad: sadismo, fetichismo, masoquismo, exhibicionismo.

2) Aquellas en las que lo perverso es el objeto: homosexualidad, paidofilia, gerontofilia, zoofilia $y$ autoerotismo.

Sin duda, la obra de Krafft-Ebing junto a la de otros psiquiatras de la época, se puede considerar fundante de un nuevo paradigma: la dupla que vuelve inseparable la sexualidad de la perversión.

Vendrell afirma:

El invento de la sexualidad, creación de 'científicos' y de médicos que también se reivindican como tales, conlleva entre otros efectos la fragmentación del campo erótico, la codificación de las 'perversiones' [...] y la patologización de conductas que hasta entonces sólo eran objeto de condena moral [...] el mismo dispositivo que construye la sexualidad 'normal' $y$ a los sujetos de ese tipo de experiencia, construye a la vez sus formas 'anormales' (2004:78 y 90).
Es justo en este momento socio-histórico cuando Foucault ubica el surgimiento de la hipótesis represiva y la implantación perversa. Hipótesis represiva no en el sentido de represión, sino para decir que hay represión, es "la puesta en discurso del sexo" (1976:19).

No de un sólo discurso sino de múltiples. Emerge, según Foucault, un incansable imperativo de hablar de sexo en las diferentes instituciones de la sociedad, hay que decirlo todo. Las instancias del poder quieren oír hablar de sexo constantemente, pero en secreto. Y no por eso se escucha menos:

Lo propio de las sociedades modernas no es que hayan obligado al sexo a permanecer en la sombra, sino que ellas se hayan destinado a hablar del sexo siempre, haciéndolo valer, poniéndolo de relieve como el secreto (Ídem. 47).

Esto conllevó a la implementación de múltiples perversiones. Ya no se pone el foco en la sexualidad de la pareja heterosexual, normal, según el discurso hegemónico, sino en todo lo demás. Expone Foucault:

... Se interroga a la sexualidad de los niños, a la de los locos y a la de los criminales (Ídem. 51).

Se enumera y clasifica las sexualidades periféricas como si fueran especies, en lugar de simples actos. Es entonces imprescindible entender las obras de Krafft-Ebing, $y$ de otros médicos de la época, a partir de estas lecturas sagaces, de Vendrell y de Foucault. Ellos las analizan como el big-bang del concepto sexualidad/perversión, indispensable para distinguir en profundidad dónde estamos posicionados con el tema de sexualidad.

Se mencionó antes: Freud presentó un cambio frente al conocimiento psiquiátrico, con respecto a la sexualidad, sin dejar de formar parte del contexto socio-histórico. Este basó su desarrollo teórico en la obra de KrafftEbing $y$ en otros psiquiatras de la época. Sin embargo, hizo un quiebre. Uno de sus conceptos revolucionarios, para su tiempo, fue el de Sexualidad Infantil, el cual lo definió como sexualidad perversa polimorfa. 
El padre del psicoanálisis postuló en su obra, en especial en Tres ensayos para una teoría sexual, publicada en 1905, que existe un proceso evolutivo de la constitución de la sexualidad, que comienza desde el nacimiento hasta la adultez. Se va transitando por varias etapas, muy difundidas, la etapa oral, anal, fálica hasta llegar a las genitalidad con la adolescencia y continúa "hasta la muerte" (Freud, 1905:179).

En este proceso, también se circula por diferentes elecciones de objeto. La sexualidad infantil, constituida por todas las etapas recién descritas, con excepción de la última, es considerada perversa polimorfa. Esto significa que presenta pulsiones parciales $y$ no integrales: se basan en una desviación en cuanto el objeto (succión, retención-expulsión, masturbación), y son autónomas; presentan diversidad de zonas erógenas que brindan placer, a diferencia de la genitalidad que muestra la primacía de una zona erógena: la genital.

La sexualidad infantil es perversa porque impone objetos $y$ metas que no son el objeto $y$ metas sexuales normales (Freud, 1905:173).

Esto significa que todos, obligatoriamente, pasamos por las diferentes perversiones del desarrollo psicosexual. Esto es una revolución, en comparación a la tajante división entre sexualidad normal y anormal de la psiquiatría del siglo XIX.

Sobre esto, Mazzuca (2001) sostiene:

... En síntesis, Freud produce un concepto de perversión que no se refiere a una patología, como el concepto original de Krafft-Ebing, sino que constituye la característica estructural, por lo tanto esencial y universal, de la sexualidad humana.

Pero si analizamos en profundidad, notamos que es una revolución aparente. Si bien postuló un concepto de perversión esencial y universal intrínseco en la sexualidad humana, consideró que en la adultez debería alcanzarse una sexualidad ideal, que puede tener ciertas tendencias perversas polimorfas, pero que se destaca por presentar una meta y objeto ideal, por llegar a una normalidad: la primacía de la zona genital.
Freud escribió:

... Con el advenimiento de la pubertad se introducen los cambios que llevan la vida sexual infantil a su conformación normal definitiva. La pulsión sexual era hasta entonces predominantemente autoerótica; ahora halla al objeto sexual. Hasta ese momento actuaba partiendo de pulsiones $y$ zonas erógenas singulares que, independientemente unas de otras, buscaban un cierto placer en calidad de única meta sexual. Ahora es dada una nueva meta sexual; para alcanzarla, todas las pulsiones parciales cooperan, al par que las zonas erógenas se subordinan al primado de la zona genital... (1905:189).

$O$ sea que la perversión esencial y universal de la sexualidad humana se refiere sólo al desarrollo psicosexual infantil. Lo anterior no quiere decir que Freud no haya hecho una distinción entre normalidad y anormalidad. De hecho, quien no llega a esta etapa final de la manera esperada y no realiza un desarrollo normal de estos estadios, es quien presenta perturbaciones. Afirmó Freud: “... Todas las perturbaciones patológicas de la vida sexual han de considerarse, con buen derecho, como inhibiciones del desarrollo..." (Ídem. 190).

En el artículo "La moral sexual 'cultural' y la nerviosidad moderna" Freud comenta acerca de las personas perversas:

... Los diversos géneros de perversos, en quienes una fijación infantil a una meta sexual provisional coartó el primado de la función reproductora, y los homosexuales o invertidos, en quienes, de una manera aún no esclarecida por completo, la meta sexual fue apartada del sexo opuesto... (1908: 170).

Sin duda, también Freud tuvo un modelo ideal de cómo debería ser la sexualidad, siguió el discurso hegemónico de la imposición de la heterosexualidad obligatoria, monogámica y reproductora como paradigma de la sexualidad normal. 
De hecho, al igual que Krafft-Ebing, Freud presentó una categorización acerca de quienes practican una sexualidad que se desvía del objeto y de la meta. En los primeros títulos del índice de Tres ensayos..., se lo puede apreciar:

I. Las aberraciones sexuales

1. Desviaciones respecto al objeto sexual

A. La inversión

B. Personas genésicamente inmaduras y animales como objetos sexuales

2. Desviaciones con respecto a la meta sexual

A. Transgresiones anatómicas

B. Fijación de metas sexuales provisionales... (1905, VII).

En las desviaciones respecto del objeto Freud incluyó la homosexualidad, el fetichismo, la zoofilia, etc. (1905:124). En las desviaciones respecto de la meta, él mencionó a las prácticas relacionadas al placer visual: exhibicionismo $y$ el voyeurismo; el placer de sufrir o hacer sufrir, sadismo y masoquismo. Y el placer por sobrestimación exclusiva de una zona erógena, por ejemplo: la boca, el ano, etc. (1905:136).

Se debe reconocer que, a diferencia de Krafft-Ebbing y otros psiquiatras de aquél período histórico, Freud no elaboró una descripción exhaustiva de la patología, sino que explicó los procesos y mecanismos psíquicos que actúan en ella. Él no encontró los orígenes en la Biología, sino en la historia infantil de cada persona. A partir de las experiencias vividas es que el sujeto presentará una neurosis, una psicosis o una perversión. Freud postuló:

... Pero hemos de decirnos, también, que esta presunta constitución que exhibe los gérmenes de todas las perversiones sólo podrá rastrearse en el niño [...]. De ese modo, nuestro interés se dirige a la vida sexual del niño, estudiaremos el juego de influencias en virtud del cual el proceso de desarrollo de la sexualidad infantil desemboca en la perversión, en la neurosis, o en la vida sexual normal... (Ídem. 156).

¿Qué ocurre para Freud en los perversos que no sucede en los neuróticos? Freud utilizó principalmente un concepto para explicar las perversiones: el mecanismo de desmentida. En su artículo Fetichismo, del año 1927, él analizó a las personas que eligieron como objeto sexual un fetiche. Adjudicó ese fenómeno al mecanismo de desmentida de la castración. Y analizó el complejo de Edipo. Freud sostuvo que hay ciertos hombres (no ocurre en mujeres según él) que reniegan de la realidad de ver a su madre castrada, sin pene. Presentó el mecanismo de defensa de la desmentida respecto a una realidad percibida (ausencia de pene) como un proceso constitutivo de la organización perversa. Pensó al fetiche como una formación de compromiso entre dos pensamientos que se contraponen: ausencia del pene en la madre $y$ atribución del pene faltante en forma del objeto-fetiche. Estas dos representaciones psíquicas, inconciliables entre sí, pueden coexistir perfectamente gracias al mecanismo de desmentida y escisión del yo (Freud, 1927:148). Es como si en el perverso se mantuviera una paradoja psíquica: consiste en saber algo de la castración mientras no se quiere saber nada de ella. Este artículo se ha tomado en el psicoanálisis como modelo para entender las otras formas de perversión.

En síntesis, si bien Freud hizo revoluciones en la manera de entender la sexualidad humana, no dejó de prescribir en qué consiste la sexualidad normal y la anormal.

¿Por qué surge esta necesidad constante de hacer una división tajante entre sexualidad normal de la anormal? ¿Por qué no presentar diferentes maneras de expresar, sentir y vivir la sexualidad?

\section{NORMALIDAD Y PATOLOGÍA EN OTTO KERNBERG}

\section{LO BIOLÓGICO COMO DETERMINANTE}

Relaciones amorosas: normalidad y patología, obra del psicoanalista Otto Kernberg, que se analiza en este trabajo, refleja con claridad la ideología del autor. Para Kernberg hay una sexualidad normal y otra patológica. Es llamativo que, a diferencia de Freud y otros psicoanalistas, Kernberg comience con un recorrido 
por los orígenes biológicos de la sexualidad; menciona cromosomas, las hormonas, etc. Llegando al punto de comparar la sexualidad humana con la de los animales como si fuera un continuo. De entrada, nos está diciendo que hay cosas que son inamovibles, naturales y que allí radica la normalidad o la anormalidad. El libro, en términos de Vendrell, se encuadra dentro de una perspectiva necesariamente esencialista. Vendrell analiza diferentes maneras de reflejar una posición esencialista, una es la hipótesis naturalista de la sexualidad: "[...] de modo que lo más profundo, lo biológico, marca más lo que somos universalmente como especie que aquello situado en la superficie: lo cultural" (2004b:39).

En el siguiente párrafo se aprecia un ejemplo claro de cómo Kernberg presenta esta perspectiva esencialista biológica:

[...] con independencia de las circunstancias de la crianza y en relación con el grupo de control, las niñas con hiperplasia adrenal congénita presentaban más conductas de marimacho, tenían menos interés en jugar con muñecas, en los bebés $y$ en adornarse, $y$ tendían a preferir juguetes como los autos y las armas [...]. Estos datos sugieren que la conducta del rol genérico de la infancia es influida por los factores hormonales prenatales (1995:33).

Suena tan absurdo que las hormonas sean las que determinen con qué le gusta jugar a la niña. Ignora por completo cómo la cultura, por diferentes caminos, va moldeando y prescribiendo el modo en que debemos comportarnos según la etiqueta que nos hayan sellado en nuestro cuerpo.

Kernberg dice "con independencia de las circunstancias de la crianza", ¿cómo se puede desentender de la crianza $y$ del mundo que educa a esa niña? De hecho, ¿cuál es el problema si una niña no quiere jugar con muñecas y prefiere autos? ¿En qué norma se basa Kernberg para darle a ese dato, carácter de llamativo? Sin duda, depende de las circunstancias de su crianza.

Vendrell, al desarrollar la perspectiva constructivista, concluye: " [...] no se trata de ver la acción de la cultura como represora de una fuerza biogenéticamente enraizada, sino como la acción de configurar e implantar en el organismo una fuerza culturalmente construida" (2004b:39).

El problema más grave con esta perspectiva surge cuando la violencia se justifica con el esencialismo biológico. Eso también parece aceptar el autor:

Hay pruebas de una mayor agresión de los machos, tanto en los seres humanos como en los primates subhumanos; esta parece una característica universal transcultural y los datos sugieren que los niveles de agresión están vinculados a las hormonas sexuales. Es probable que la predisposición masculina a la agresión se extienda a la conducta de dominio, la competitividad $y$ el nivel de actividad (Kernberg,1995:32).

Si desde el punto de vista biológico el hombre es más agresivo, ino hay nada que hacer más que aceptar los golpes que vienen de la naturaleza!

Cientos de feministas que trabajan con el tema de violencia contra las mujeres, encuentran reiteradamente este modelo de pensamiento. El asunto se complica aún más cuando encontramos ese supuesto en ciertas literaturas feministas. Me refiero a cierto feminismo cultural, catalogado por Raquel Osborne como esencialista. Esa línea de pensamiento construye una contracultura femenina, jerarquizándola por encima de la masculina: lucha por los derechos de las mujeres, $y$ sin querer, termina cayendo en el mismo discurso patriarcal. Por ejemplo, una de las afirmaciones del feminismo cultural: "La sexualidad masculina es agresiva, irresponsable, orientada genitalmente y potencialmente letal. La sexualidad femenina se manifiesta de forma difusa, tierna y se orienta a las relaciones interpersonales" (Osborne, 2002:41).

Esto demuestra lo difícil que es salirse de los discursos hegemónicos, pareciera que cuánto más uno se rebela y va contra la corriente, sin darse cuenta, vuelve al camino principal. Por eso el gran desafío es ir deconstruyendo $y$ reconstruyendo estudios, reflexiones y análisis. 
CULPABILIDAD DE LA MADRE

Otra variable determinante para Kernberg del tipo de identidad sexual que adquiere el sujeto, dentro del campo de lo normal o de lo patológico, es el papel que juega la madre. Podría traer a colación varias citas en las que se atribuye a la madre la constitución de alguna patología sexual en su hijo o hija. Por ejemplo:

... la exploración psicoanalítica de niños con identidad sexual anormal, así como la historia de los adultos transexuales [...] se cuentan entre esas pautas una madre con fuertes componentes bisexuales de la personalidad, distante de un esposo pasivo o inaccesible, $y$ que absorbe al hijo como provisión simbólica de completamiento para ella misma (1995: 28).

Kernberg llegó al punto de citar el papel central que juega la madre de los monos en la constitución sexual de sus crías:

[]... un apego adecuado obtenido mediante un contacto seguro, físicamente estrecho, entre la cría y la madre es esencial para que se desarrolle una respuesta sexual normal en los monos adultos: la ausencia de un quehacer materno normal [...] destruye la ulterior capacidad para la respuesta sexual adulta (1995:29).

¿Cuál es la respuesta sexual anormal en los monos? ¿Cómo se manifiesta? La obsesión por ejercer poder, ¿llegó también a los monos? Parece que a ellos también les toca ser clasificados y etiquetados por sus conductas sexuales; al menos según Kernberg.

Esta variable del rol materno tiene que ver con la forma en que está estructurada la sociedad en que vivimos: culpar a las madres es una de las estrategias para mantener marginadas y subordinadas a las mujeres. ¿Qué mayor sentencia que culpar a una persona por las patologías de su hijo o hija! No se culpa al padre sino a la madre y con demasiada facilidad.

Mabel Burin, al mencionar su experiencia clínica, rompe un poco con esta idea que necesariamente la madre es la causante de la constitución psíquica de sus hijos:

En mi experiencia clínica con mujeres homosexuales he hallado que, si bien muchas de ellas presentaban tales rasgos de vínculos tempranos persecutorios con sus madres, no todas tenían tales características, $y$ varias de ellas denotaban vínculos con sus madres que no diferían marcadamente de los que tenían muchas mujeres heterosexuales (2001: 95).

Burin intenta demostrar que no siempre la madre es la causante de la identidad sexual de sus hijos o hijas, pero no termina de sacarla de ese lugar culpógeno. Además, al tener como parámetro a las madres de hijas heterosexuales, de alguna manera, sigue pensando de forma binaria: normal/anormal. Se basa en un paradigma heterocéntrico de la sexualidad, en el que la heterosexualidad es la norma a partir de la cual se evalúa también la homosexualidad.

\section{SEXUALIDAD MADURA / SEXUALIDAD PATOLÓGICA}

En coherencia con el título del libro, continuamente, Kernberg distingue la sexualidad madura de la anormal o la patológica. Por ejemplo:

En circunstancias normales, la excitación sexual en el individuo maduro se activa en el contexto del deseo erótico [...] En circunstancias patológicas, incapacidad para el deseo erótico, con una manifestación de excitación sexual azarosa, difusa, no selectiva y perpetuamente insatisfecha, o incluso a una falta de capacidad para experimentar excitación sexual (1995: 43 y 44).

En relación con las circunstancias patológicas, ¿será cierto que les va tan mal sexualmente? ¿O quizá sólo se trata de la imposibilidad de ver $y$ de saber que algo puede ser diferente?, ¿Tal vez hay cierta negación a aceptar que se puede disfrutar de otra manera a la prescrita? ¿No estará Kernberg haciendo una desmentida de lo que los perversos gozan? 
Sin duda, esta tajante división es muy llamativa. ¿Por qué será que debemos constantemente discriminar lo que está bien y mal en relación con la sexualidad?

En este sentido, es brillante el análisis que hace Gayle Rubin, en su trabajo Reflexionando sobre el sexo: notas para una teoría radical de la sexualidad. Ella analiza la manera en que se jerarquiza, por lo general, a la sexualidad. En un extremo está el sexo considerado bueno, normal, natural, saludable y sagrado. En el otro, el sexo malo, anormal, antinatural, dañino y pecaminoso y extravagante (1984:140-141). En el medio, diferentes matices.

La propuesta de esta autora es, que en vez de levantar fronteras entre el sexo bueno $y$ malo, jerarquizándolo:

... [se] debería juzgar los actos sexuales por la forma en que se tratan quienes participan en la relación amorosa, por el nivel de consideración mutua, por la presencia o ausencia de coerción y por la cantidad y calidad de placeres que aporta. El que los actos sean homosexuales o no, en parejas o grupos, desnudos o en ropa interior, libres o comerciales, con o sin video, no debería ser objeto de preocupación ética (Ídem. 142).

$\mathrm{Su}$ idea es pensar la sexualidad desde una ética sexual pluralista, teniendo en cuenta el concepto de variedad sexual benigna (Ídem. 142). Rubin sostiene que la variedad es una propiedad fundamental de toda forma de vida $y$ el interrogante que nos formula es por qué, a diferencia de otras facetas de la vida, la sexualidad debe adaptarse a un modelo único, ideal y superior (Ídem. 142).

Volviendo al concepto de amor sexual maduro -implica que hay otro que es inmaduro-, postula Kernberg:

El amor sexual maduro expande el deseo erótico y lo convierte en una relación con una persona específica, en la cual la activación de las relaciones inconscientes del pasado y las expectativas conscientes de una vida futura como pareja se combi- nan con la puesta en marcha de un ideal del yo conjunto. El amor sexual maduro implica un compromiso en los ámbitos del sexo, las emociones $y$ los valores (1995: 44).

¡Muy romántico! Y demasiado sesgado. Para empezar, Kernberg da por sentado que el amor maduro emerge en una relación heterosexual, negando otro tipo de relaciones. También supone que se debe vivir toda la vida con quien se tiene relaciones sexuales: "la selección madura de la persona que uno ama y con la cual quiere pasar su vida involucra ideales maduros, juicios de valor y metas que, aparte de satisfacer las necesidades de amor e intimidad, le procuran un sentido más amplio de la vida" (Ídem. 117).

Kernberg parece no poder escindir las relaciones sexuales de ideales, valores, amor, etc. ¿Y si alguien pretende tener relaciones sexuales, sin compartir valores, metas, futuro en común, etc.? ¿Sería un amor sexual inmaduro?

Otto Kernberg menciona que quienes presentan patologías narcisistas no tienen capacidad de enamorarse siendo esta "un pilar básico de la relación de pareja. Supone la capacidad para vincular la idealización al deseo erótico, y el potencial para establecer una relación objetal profunda" (Ídem. 109).

Sin duda, este autor, naturaliza los ideales y los valores del romanticismo del mundo de rosas, ignora que son una construcción sociohistórica.

Desde los estudios de género, y también desde otras disciplinas, sabemos que el surgimiento de los conceptos de enamoramiento y de amor romántico, se los puede ubicar en un momento determinado de la historia de la humanidad. Phillip Ariés estudió el amor en el matrimonio; él distinguió un punto de inflexión a partir del siglo XVIII, cuando la sociedad tendió a constituir un ideal de matrimonio que impuso a los esposos la necesidad de amarse. (1987: 94).

Ana María Fernández afirma: "En la historia social de Occidente, el matrimonio por amor es una figura muy reciente, como también es un anhelo reciente la expectativa de que 
algo del placer sexual de las mujeres se juegue en tal institución" (1994:17).

La autora -además de otros académicos-, ubica el nuevo tipo de contrato matrimonial: el matrimonio por amor en la familia burguesa $y$ en el advenimiento de la sociedad industrial. Cita al historiador Shorter, quien ha llamado a esta época: la revolución sentimental del S. XVIII (Ídem. 200).

Estos desarrollos teóricos demuestran que el psicoanalista Otto Kernberg mira la realidad desde una determinada concepción, que tiene sus raíces en el siglo XVIII, y desconoce que esas ideas no son una manera necesaria de concebir las relaciones, sino una construcción cultural.

En el libro "Extrañas parejas: psicopatología de la vida erótica", José E. Milmaniene sostiene: "La extrema disparidad entre los miembros de una pareja perversa siempre alude a la que existe entre un amo y un esclavo" (1998:80).

Este autor habla de un amo y de un esclavo en las parejas perversas, como característica patológica. Se desentiende de la manera en que se desenvuelven, en gran porcentaje, las relaciones de las parejas heterosexuales. El concepto de amor moderno ignora la dinámica amo y esclava, las luchas de poder que se dan en las relaciones de pareja, la jerarquía —intrínseca en estos vínculos-y la limitación de las mujeres a tener un espacio propio de libertad, autonomía y desarrollo personal.

Clara Coria describe:

... se trata de una construcción social del amor que instala el juego amoroso como un intercambio jerarquizado entre quienes se aman. En otras palabras, entre dos personas de las cuales una se considera a sí misma como sujeto, en posesión de su deseo, con un potencial amatorio que le es propio $y$, por lo tanto, que no pierde aunque cambie de amores, $y$ otra persona que, en cambio, pareciera quedar a merced del deseo del otro, haciendo lo imposible por satisfacer su expectativa creyendo que de esa manera garantiza el amor (2005:93).
Entonces queda bastante alejado de la realidad decir que el matrimonio heterosexual es el modelo ideal de sexualidad y que otras maneras de expresar la sexualidad, fuera de este marco, son patológicas. Estos ideales de amor romántico y parejas heterosexuales son producto de un momento socio-histórico determinado.

Con este criterio hoy puede concebirse patológico que alguien no tenga la capacidad de enamorarse, y mañana la misma situación podrá ser vista como una manera más saludable de vivir.

De alguna manera esto es lo que Gayle Rubin intenta cuestionar, trae a colación la lucha de mujeres lesbianas sadomasoquistas por "un reconocimiento de la diversidad erótica y una discusión más abierta sobre la sexualidad" (1984:177).

¿Quién dice qué está bien y qué está mal? ¿Quién determina qué es normal y qué es anormal en relación con la sexualidad? Deberíamos hacernos esas preguntas continuamente.

\section{PERVERSIONES SEGÚN OTTO KERNBERG}

Kernberg, $y$ otros psicoanalistas, basándose en la obra de Freud, desarrollaron y analizaron diferentes tipos de perversiones, hasta el día de hoy. A continuación se citan menciones del libro de Otto Kernberg sobre algunas de las prácticas consideradas perversiones hasta la actualidad, para luego analizarlas:

\section{Transexualidad:}

... los transexuales también presentan distorsiones severas en otras áreas de identidad (1995: 31).

[No sólo en relación con la sexualidad sino que son pura distorsión. Esta afirmación se puede entender con el análisis que hace Vendrell sobre la centralidad de la sexualidad en la época moderna]: "identidad sexual" (...) esa identidad es "la identidad", es decir, aquello que fundamentalmente somos y por lo que primariamente nos definimos, nos reconocemos y se nos reconoce (2004b:84). 


\section{Sadomasoquismo:}

En la relación emocional de la pareja puede observarse una perversidad concomitante en las relaciones sadomasoquistas prolongadas... (Ídem. 159). Es probable que las relaciones masoquistas persistentes sin intervención de terceros sean las manifestaciones más frecuente de la patología severa del superyó (...) en el largo plazo las interacciones sadomasoquistas también afectan el funcionamiento sexual de la pareja (Ídem. 193).

\section{Exhibicionismo:}

Lo mismo que las otras perversiones, la exhibicionista es una desviación sexual típica de los hombres... (Ídem. 62).

\section{Masturbación:}

Pero la masturbación como actividad compulsiva, repetitiva (...) genera un deterioro de la excitación, del placer y de la satisfacción... (Ídem. 91).

Si se repite quizá sea, justamente, porque hay excitación, placer y satisfacción. Para Kernberg, ¿constituye un problema que estas emociones se sientan sin penetración vaginal?

\section{Masoquismo:}

... al igual que todas las perversiones sexuales, el masoquismo es más frecuente en los hombres... (Ídem. 224).

\section{Sexo en grupo:}

Pueden ilustrar la perversidad en el encuentro sexual los desarrollos típicos de las parejas que participan durante un cierto lapso en sexo grupal. Entre seis meses a un año después de la participación regular en actividades perversas polimorfas múltiples, desaparece la capacidad de estas parejas para la intimidad sexual (Ídem. 159).

Una vez más, la advertencia y la amenaza: no volver a gozar de la verdadera sexualidad si se continúa desviados del camino.

Estas citas dicen mucho: muestran cuán internalizado está este sistema normalidad/ patología y cómo, aún en la era posmoderna, postestructuralista, podemos leer estos párrafos en libros contemporáneos, de pretendida vigencia. Con el agregado que estos conceptos se aplican a diario, en tratamientos terapéuticos, que tratan de normalizar lo anormal. ¿Cómo se puede sentir alguien que ejerce alguna de esas prácticas sexuales? ¿Cuál será la primera reacción? ¿Vergüenza? ¿Culpa? ¿Se sentirá diferente? ¿Qué le ocurre al lector que no ejerce estas prácticas? ¿Se siente orgulloso de no entrar en estas categorías? ¿Mira con malos ojos cuando se entera de alguien que las practica?

Sin duda estamos bajo una de las estrategias del saber-poder-placer que formula Foucault:

Proliferación de las sexualidades por la extensión de poder: aumento del poder al que cada una de las sexualidades regionales ofrece una superficie de intervención (1976: 63) (...) toda una titilación visible de lo sexual que emana de la multiplicidad de los discursos, de la obstinación de los poderes y de los juegos del saber con el placer (Ídem. 91).

Quizá por eso está tan anclado en la sociedad, son demasiadas las personas que no quieren, no están dispuestas a renunciar a tanto saber, poder y placer.

\section{REFLEXIONES FINALES}

Más que elaboradas respuestas, surgen numerosos interrogantes: ¿por qué aún hoy, se usan textos como el analizado? ¿Por qué se siguen aplicando esas ideas? ¿Es más fácil leer 
lo que escribió Krafft-Ebbing en el siglo XIX, que leer un libro de 1995? ¿Y por qué en 1995 se repite, de alguna manera u otra, ese mismo discurso, la misma discriminación? ¿Será posible, alguna vez, pensar en sexualidad sin dicotomizar entre normal y anormal? ¿Podrán ser consideradas las llamadas perversiones maneras posibles de expresar la sexualidad?

Es harto complejo determinar cuál es el mejor posicionamiento frente a la temática de la sexualidad. Lo que se hizo hasta el momento en materia de sexualidad no es demasiado aconsejable. No puede ser favorable que seamos etiquetados, y que un rótulo condicione nuestro destino. Tampoco puede ayudar que algunas fórmulas sean deseadas y otras, odiadas. Y no puede favorecer que nos hagan la vida difícil por llevar en la carne un sello que no solicitamos. No es bueno que se margine, discrimine ni que no se respete la diversidad. Foucault lo expresa claramente: "Al más discreto acontecimiento en la conducta sexual, accidente o desviación, déficit o exceso, se lo supone capaz de acarrear las consecuencias más variadas a lo largo de toda la existencia" (1976: 82-83).

El control es tan grande que ante un pequeño movimiento alejado de lo esperado... se nos condena con determinada identidad para toda la vida. Pareciera no haber escape posible a ese sello, es una marca para la eternidad.

Los seres humanos encarnamos un misterio, con riqueza y potencial inimaginable, ¿para qué reducirnos a una identidad rígida?, ¿por qué limitarnos a creer que ya está escrito todo nuestro comportamiento y todas las maneras de deber ser? Esas actitudes limitan, impiden descubrir otras formas de existencia, otras maneras de actuar. En este sentido son interesantes las ideas de Judith Butler: ¿por qué no pensar en un escenario, en personajes, dándonos la libertad de actuar diferentes libretos? No tan estipulados ni estereotipados. La autora afirma que vivimos actuando pero tratamos de encajar con los libretos hegemónicos: "El acto que uno hace, el acto que uno ejecuta, es, en cierto sentido, un acto que ya fue llevado a cabo antes de que uno llegue al escenario" (1998:306).
Es complicado cambiar nuestro sistema de vida; es difícil superar costumbres, mandatos, herencias. El desafío es tomar conciencia $y$ cuestionarnos la forma en que percibimos $y$ construimos nuestras sexualidades. Por lo menos, es importante darse la oportunidad, en el ámbito académico, de pensar y de cuestionar la sexualidad construida hasta la actualidad, sin miedos ni tapujos, sin prejuicios ni certezas, sin advertencias ni peligros. Simplemente intentar liberarnos por un momento de las ataduras cotidianas.

\section{BIBLIOGRAFÍA}

Aries, Ph. El amor en el matrimonio. Sexualidades occidentales. Ph. Aries, A. Béjin, M. Foucault y Otros. Argentina: Editorial Paidós, 1987.

Butler, Judith. "Actos preformativos y constitución del género: un ensayo sobre fenomenología y teoría feminista”. Debate Feminista 18. 1998.

Burin, Mabel. (1998). La familia: sexualidades permitidas y prohibidas. Género y Familia: Poder, amor y sexualidad en la construcción de la subjetividad. Eds: Burin, Mabel y Meler, Irene. $2^{\text {a }}$ reimpresión. Argentina: Editorial Paidós, 2001.

Coria, Clara. (2001). El amor no es como nos contaron... ni como lo inventamos. $3^{\mathrm{a}}$ reimpresión. Argentina: Editorial Paidós, 2005.

Fernández, Ana María. (1993). La mujer de la ilusión: Pactos y contratos entre hombres y mujeres. $1^{\mathrm{a}}$ reimpresión. Argentina: Editorial Paidós, 1994.

Foucault, Michel (1976). Historia de la sexualidad. La voluntad del saber. Trad. Ulises Guiñazú. 23a edición. México: Siglo Veintiuno, 1996. 
Freud, S. (1905). "Tres ensayos para una teoría sexual". La metamorfosis de la pubertad. Obras Completas VII. Trad. de José L. Etcheverry. $8^{\text {ava }}$ reimpresión. Argentina: Amorrortu Editores, 1995.

Freud, S. (1908). "La moral sexual cultural' y la nerviosidad moderna”. Obras Completas IX. Trad. de José L. Etcheverry. Tercera reimpresión. Argentina: Amorrortu Editores, 1993.

Freud, S. (1923). "Organización genital infantil”. Obras Completas XIX. Trad. de José L. Etcheverry. $4^{a}$ reimpresión. Argentina: Amorrortu Editores, 1994.

Freud, S. (1927). "Fetichismo". Obras Completas Xxi. Trad. de José L. Etcheverry. $4^{\mathrm{a}}$ reimpresión. Argentina: Amorrortu Editores, 1994.

Kernberg, Otto (1995). Relaciones amorosas: normalidad y patología. Traducción al español de Jorge Piatigorsky. $2^{\text {da }}$ reimpresión. Argentina: Ed. Paidós, 1998.

Krafft-Ebing, R.Von (1886). Psichopathia Sexualis. Traducido de la $12^{\text {ava }}$ edición del alemán por Franklin F. Klaff. Estados Unidos: Arcade Publishing Inc., 1998.

Mazzuca, Roberto. "La categoría clínica de la perversión en el psicoanálisis".
Conferencia presentada en el octavo Congreso Internacional de psiquiatría organizado por la Asociación de Psiquiatras. Mesa redonda. Temas de Psicopatía. Buenos Aires, 2001.

Milmaniene, José. Extrañas parejas: psicopatología de la vida erótica. Argentina: Ed. Paidós, 1998.

Osborne, Raquel. (1993). La construcción social de la realidad. $2^{\text {a }}$ edición. España: Ediciones Cátedra, 2002.

Rubin, Gayle. Reflexiones sobre el sexo: notas para una teoría radical de la sexualidad. Placer y Peligro. Explorando la sexualidad femenina. Carole S. Vance (comp.). $2^{a}$ edición. Madrid: Talasa, 1989.

Vendrell, Joan. El debate esencialismoconstructivismo en la cuestión sexual. Sexualidades diversas. Aproximaciones para su análisis. Gloria Careaga y Salvador Cruz (eds.). México: PUEG, 2004.

Vendrell, Joan. La centralidad de la sexualidad en la era moderna. Sexualidades diversas. Aproximaciones para su análisis. Gloria Careaga y Salvador Cruz (eds.). México: PUEG, 2004. 